\title{
Determination of the Crystal Structure of $\mathrm{La}_{0.9} \mathrm{Sr}_{0.1} \mathrm{Ga}_{0.8} \mathrm{Mg}_{0.2} \mathrm{O}_{3-\delta}$
}

\author{
Jie Zhang ${ }^{1,2, a}$, Chenggang $\mathrm{Li}^{1, \mathrm{~b}}$ and Weiguang Chen ${ }^{1, \mathrm{c}}$ \\ ${ }^{1}$ College of Physics and Electronic Engineering, Zhengzhou Normal University, Zhengzhou \\ 450044, China \\ ${ }^{2}$ School of Physics and Engineering, Zhengzhou University, Zhengzhou 450052, China \\ ajiezhang76@126.com, bscu_lcg@163.com, 'c11954300@qq.com
}

Keywords: Solid oxide fuel cells (SOFCs); Laser rapid sintering (LRS); Solid state reaction (SSR); Crystal structure; X-ray Diffraction.

Abstract. X-ray diffraction spectra are studied in the two series of $\mathrm{La}_{0.9} \mathrm{Sr}_{0.1} \mathrm{Ga}_{0.8} \mathrm{Mg}_{0.2} \mathrm{O}_{3-\delta}$ (denoted as LSGM). The comparison of the enlarged portion of XRD spectra between the experimental samples and samples in the card bas has been made to detemine their crystal structures at room temperature. The comparison results reveal that the two series of samples of $\mathrm{La}_{0.9} \mathrm{Sr}_{0.1} \mathrm{Ga}_{0.8} \mathrm{Mg}_{0.2} \mathrm{O}_{3-\delta}$ crystallized in different structures by different synthetic routes. It suggests that the sample prepared by solid state reactions can be identified as monoclinic (I2/a, No.15) phase, whereas the other sample by laser rapid solidification belongs to orthorhombic (Imma, No. 74) phases. The results of determination of crystal structure from the comparison of experimental XRD spectra to that in card base were in consistent with the analysis of Vasylechko's structure models.

\section{Introduction}

There is a growing need for more environmentally friendly and efficient means of energy conversion. At the forefront of this is the solid oxide fuel cell (SOFC), which it is hoped will find widespread application in the conversion of chemical to electrical energy. One of the problems of this cell is the high temperature $\left(1000^{\circ} \mathrm{C}\right)$ required to obtain reasonable oxide ion conduction for the electrolyte, traditionally yttria-stabilized zirconia (YSZ). Although there are technological advantages to high-temperature operation, it does place constraints on materials selection and on the lifetime of the fuel cell. Ishihara et al. have reported high oxide ion conductivity in the perovskite system $\mathrm{LaGaO}_{3}$ doped with $\mathrm{Sr}$ on the $\mathrm{La}$ site and $\mathrm{Mg}$ on the $\mathrm{Ga}$ site $[1,2]$. The oxide ion conductivity at $850^{\circ} \mathrm{C}$ for the composition $\mathrm{La}_{0.9} \mathrm{Sr}_{0.1} \mathrm{G}_{\mathrm{a} 0.8} \mathrm{Mg}_{0.2} \mathrm{O}_{3-\delta}$ (LSGM) is similar to that of YSZ at $1000^{\circ} \mathrm{C}$. Use of this electrolyte would therefore allow a lower fuel cell operation temperature. Fuel cell operation has indeed been demonstrated at lower temperatures using this material as the electrolyte [3-6].

Because the electrical conductivity of the samples is affected by their crystal structures, it is necessary to explore the crystal structure of LSGM. Nevertheless, there are uncertainties concerning the crystal structure. $\mathrm{La}_{0.9} \mathrm{Sr}_{0.1} \mathrm{Ga}_{0.8} \mathrm{Mg}_{0.2} \mathrm{O}_{3-\delta}$ (LSGM) has been reported to be cubic [7,8], orthorhombic [9,10] and monoclinic[11,12] at room temperature (denoted as RT). In addition, contradictory reports about the crystal structure of this solid solution exist, including some on the structure of $\mathrm{La}_{0.9} \mathrm{Sr}_{0.1} \mathrm{Ga}_{0.8} \mathrm{Mg}_{0.2} \mathrm{O}_{3-\delta}$ at elevated temperature. For example, Feng [7] and $\mathrm{N}$. Trofimenko [8] declared a cubic structure with space group Pm-3m (No. 221) for LSGM at room temperature (RT); Drennan et al. [9] by X-ray diffraction, scanning and transmission electron microscopy found LSGM orthorhombic with space group of Pnma (No. 62) at room temperature, and rhombohedral above $172^{\circ} \mathrm{C}$, while Lerch et al.[10]carried out powder neutron diffraction measurements and concluded that crystal structure of LSGM was orthorhombic with space group of Imma (No. 74) at room temperature and cubic with space group (No. 221) at $800^{\circ} \mathrm{C}$, respectively. More complicated structural changes in LSGM have been detected by Slater [12], who claimed that LSGM1020 has monoclinic structure with space group of I2/a (No.15) at room temperature, and two-phase transitions appear between 723 and 1273 K: monoclinic(pseudo-OR)-monoclinic(pseudo-Rh)-rhombohedral (R3c). Based on high-resolution X-ray diffraction measurement Vasylechko et al. [11] concluded that the crystal structure of 
$\mathrm{La}_{0.9} \mathrm{Sr}_{0.1} \mathrm{Ga}_{0.8} \mathrm{Mg}_{0.2} \mathrm{O}_{3-\delta}$ was monoclinic with space group of I2/a (No.15) at room temperature and Two transitions at 770K (I2/a-R3c) and in the range 870-970K (R3c-R-3c) occur.

In this article, using the examples of two series of samples, we present a study on the crystal structure in the system $\mathrm{La}_{0.9} \mathrm{Sr}_{0.1} \mathrm{Ga}_{0.8} \mathrm{Mg}_{0.2} \mathrm{O}_{3-\delta}$, monoclinic with space group of I2/a (No.15) and orthorhombic with space group of Imma (No. 74). XRD spectra of two samples, I2/a and Imma in card base are enlarged to determine the crystal structure of the two series of samples. The comparison of the enlarged portion of XRD spectra between the experimental samples and samples in the card base has been made to identify the different crystal structure. The results of determination were in agreement with the analysis of Vasylechko's structure models [11]. The crystal structure of two series of samples were clearly determination, which may lay foundation to the study on the relations between the electrical conductivity and crystal structures of $\mathrm{La}_{0.9} \mathrm{Sr}_{0.1} \mathrm{Ga}_{0.8} \mathrm{Mg}_{0.2} \mathrm{O}_{3-\delta}$.

\section{Experiment}

$\mathrm{La}_{0.9} \mathrm{Sr}_{0.1} \mathrm{Ga}_{0.8} \mathrm{Mg}_{0.2} \mathrm{O}_{3-\delta}$ (LSGM) samples were prepared with starting materials of $\mathrm{Ga}_{2} \mathrm{O}_{3}(99.99 \%)$, $\mathrm{La}_{2} \mathrm{O}_{3}(99.99 \%), \mathrm{MgO}(98 \%)$ and $\mathrm{SrCO}_{3}(99 \%) . \mathrm{MgO}$ and $\mathrm{La}_{2} \mathrm{O}_{3}$ were fired at $1273 \mathrm{~K}$ for 7 hours before weighting to decompose carbonate and hydroxide impurities. The absence of impurities in the reagents was checked by X-ray diffraction (XRD). The mixtures were ground in a mortar for $2 \mathrm{~h}$ and then pressed into cuboid bars $(40 \mathrm{~mm} \times 5 \mathrm{~mm} \times 5 \mathrm{~mm})$ by uni-axial cold press with a steel mould at a pressure of $10 \mathrm{MPa}$ and dried for $2 \mathrm{~h}$ at $100^{\circ} \mathrm{C}$ in a baking oven before sintering. The synthesis was performed by using a $5 \mathrm{~kW}$ continuous-wave $\mathrm{CO}_{2}$ laser. The laser beam was striking onto a bar placed at a distance where the defocus length was set to $120 \mathrm{~mm}$. The beam spot on the sample was approximately $12 \mathrm{~mm}$ in diameter. As the laser beam moves ahead along the length direction, the synthesized sample behind cools naturally and rapidly to room temperature. Such cooling process can be regarded as rapid solidification. Under optimized synthetic conditions around 1000-1100 W laser power and $1 \mathrm{mms}^{-1}$ scan speed, the first series of pure LSGM phase can be produced within a few seconds (denoted as LRS). For comparison, the second series of samples were prepared by conventional solid state reactions with pressed pellets by calcinating at $1250^{\circ} \mathrm{C}$ for $10 \mathrm{~h}$ and then sintering at $1500^{\circ} \mathrm{C}$ for $6 \mathrm{~h}$ and at $1600^{\circ} \mathrm{C}$ for $2 \mathrm{~h}$ with intermediate grindings (denoted as SSR).

The room-temperature $\mathrm{x}$-ray-diffraction (XRD) patterns were carried out using an X'Pert PRO X-Ray Diffractometer. The results of XRD pattern at room temperature of LSGM were enlarged and used to compare to the enlarged portion of three kinds of crystal structures in card base to determine the crystal structure of two series of samples.

\section{Results and Discussions}

Figure 1 shows the XRD patterns of $\mathrm{La}_{0.9} \mathrm{Sr}_{0.1} \mathrm{Ga}_{0.8} \mathrm{Mg}_{0.2} \mathrm{O}_{3-\delta}$ powders synthesized by solid state reaction at respectively $1250^{\circ} \mathrm{C}$ for $10 \mathrm{~h}, 1500^{\circ} \mathrm{C}$ for $6 \mathrm{~h}$ and $1600^{\circ} \mathrm{C}$ for $2 \mathrm{~h}$ (SSR) and laser rapid sintering (LRS) with $1100 \mathrm{~W}$ laser powers at $1 \mathrm{mms}^{-1}$ scan speed (LRS). It can been seen that the pure $\mathrm{La}_{0.9} \mathrm{Sr}_{0.1} \mathrm{Ga}_{0.8} \mathrm{Mg}_{0.2} \mathrm{O}_{3-\delta}$ phase can be obtained by SSR and LRS. To determine the crystal structure of the prepared $\mathrm{La}_{0.9} \mathrm{Sr}_{0.1} \mathrm{Ga}_{0.8} \mathrm{Mg}_{0.2} \mathrm{O}_{3-\delta}$, we selected three closest spectra in the card base, cubic (Pm-3m), monoclinic (I2/a) and orthorhombic (Imma) structure respectively. Figure 2 shows XRD comparison between the sample SSR and card base (a) Full spectrum and enlarged portion at (b) $2 \theta$ $=32.4^{\circ}$, (c) $2 \theta=104^{\circ}$ and (d) $2 \theta=123.5^{\circ}$. From Figure 2 the spetrum of the sample by SSR are agreeable with that of monoclinic (I2/a) among the three structures, so the sample by SSR can be identified as monoclinic (I2/a, No.15) phases without doubt. Similarly Figure 3 shows XRD comparison between the sample LRS and card base (a) Full spectrum and enlarged portion at (b) $2 \theta$ $=32.4^{\circ}$, (c) $2 \theta=104^{\circ}$ and (d) $2 \theta=113.5^{\circ}$. It can be seen that the spectrum of LRS sample is the closest to that of orthorhombic (Imma, No. 74) phase among the three possible structures. 


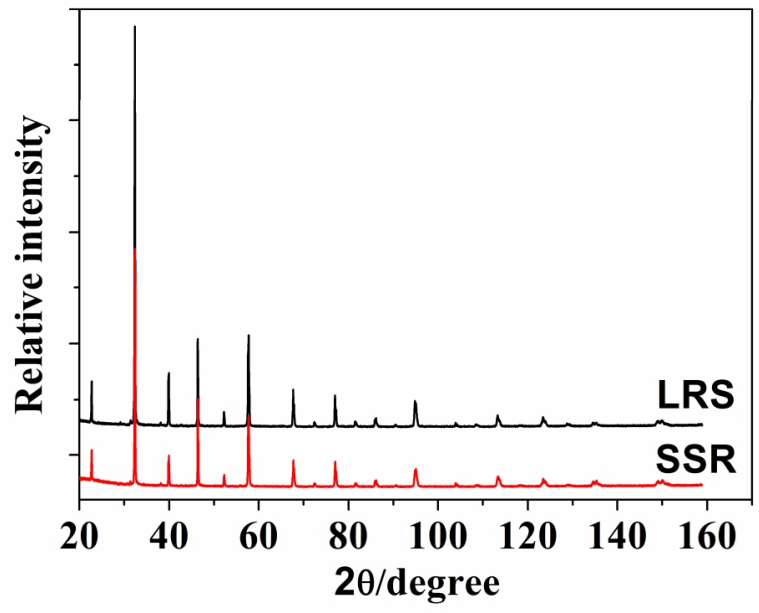

Figure 1. XRD patterns of $\mathrm{La}_{0.9} \mathrm{Sr}_{0.1} \mathrm{Ga}_{0.8} \mathrm{Mg}_{0.2} \mathrm{O}_{3-\delta}$ powders synthesized by solid state reaction at respectively $1250^{\circ} \mathrm{C}$ for $10 \mathrm{~h}, 1500^{\circ} \mathrm{C}$ for $6 \mathrm{~h}$ and $1600^{\circ} \mathrm{C}$ for $2 \mathrm{~h}$ (SSR) and laser rapid sintering (LRS) with $1100 \mathrm{~W}$ laser powers at $1 \mathrm{mms}-1 \mathrm{scan}$ speed.

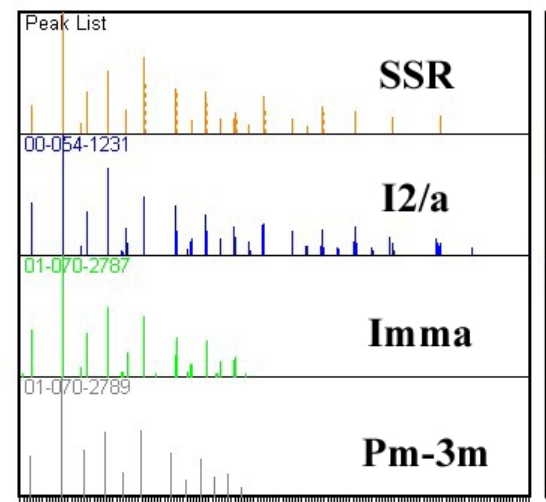

2030405060708090100110120130140150160170 Position [2Theta]

(a)

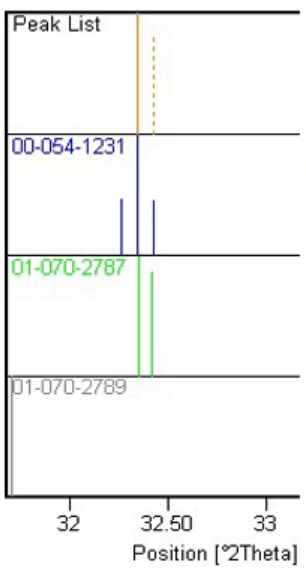

(b)

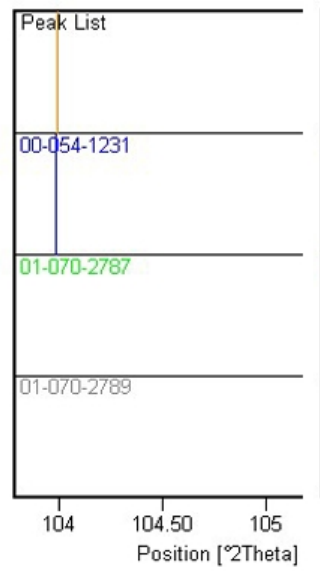

(c)

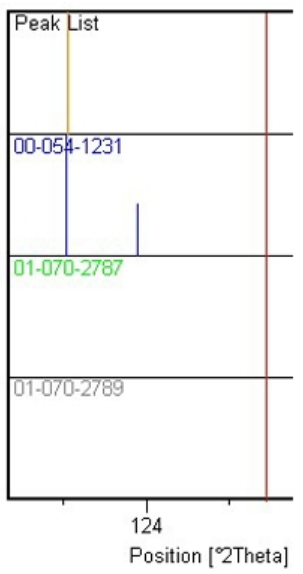

(d)

Fig. 2 XRD comparison between the sample SSR and card base (a) Full spectrum and enlarged portion at (b) $2 \theta=32.4^{\circ}$, (c) $2 \theta=104^{\circ}$ and (d) $2 \theta=123.5^{\circ}$.

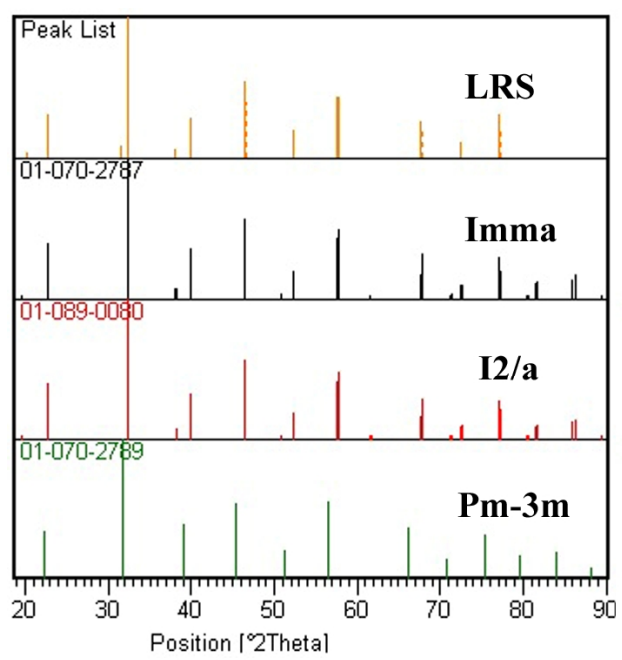

(a)

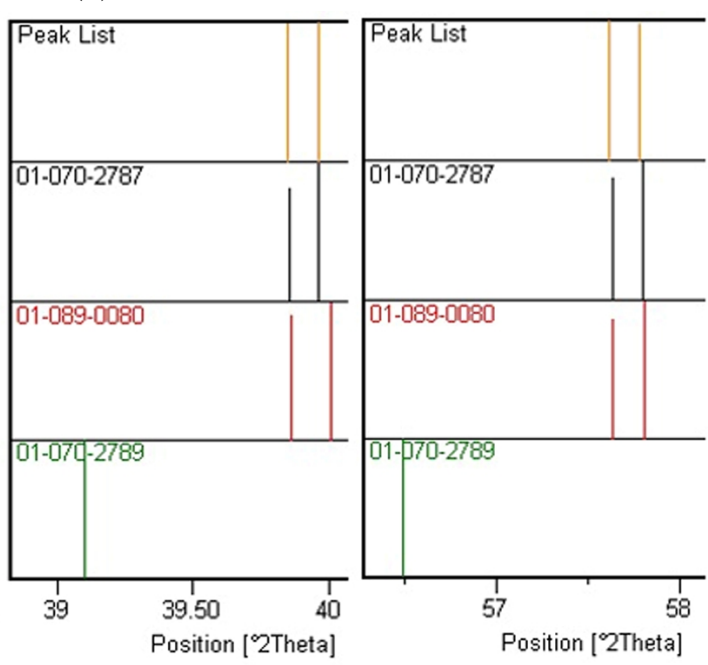

(b)

(c)

Fig.3 XRD comparison between the sample LRS and card base (a) Full spectrum and enlarged portion at (b) $2 \theta=39.9 \circ$, (c) $2 \theta=57.7 \circ$. 
Based on high-resolution X-ray diffraction measurement Vasylechko et al. [11] provided fitting profile of RT (room temperature) $\mathrm{La}_{0.9} \mathrm{Sr}_{0.1} \mathrm{Ga}_{0.8} \mathrm{Mg}_{0.2} \mathrm{O}_{3-\delta}$ of orthorhombic (Imma) and monoclinic (I2/a) structure between experimental and calculated profiles. According to the models of I2/a and Imma [3], it is reasonable that SSR (Figure 2) can be refined in a monoclinic structure with space group I2/a, while LRS (Figure 3) possesses to an orthorhombic structure with space group Imma. The result matches well with our XRD analysis of the enlarged portion.

\section{Conclusions}

The crystal structures of $\mathrm{La}_{0.9} \mathrm{Sr}_{0.1} \mathrm{Ga}_{0.8} \mathrm{Mg}_{0.2} \mathrm{O}_{3-\delta}$ prepared by solid state reactions and laser rapid solidification have been studied by X-ray diffraction and Vasylechko's structure models. The comparison of XRD enlarged portion between the samples and card base reveals that the sample crystallized in different structures by different synthetic routes. The comparison suggests that the samples prepared by solid state reactions and laser rapid solidification can be identified as monoclinic (I2/a, No.15) and orthorhombic (Imma, No. 74) phases, respectively. This is in agreement with the analysis of Vasylechko's structure models.

\section{Acknowledgements}

This work was financially supported by Science and technology plan projects of henan province (172102210115) and the Key Scientific Research Project of Henan College (17B480003).

\section{References}

[1] T. Ishihara, H. Matsuda, and Y. Takita: J. Am. Chem. Soc. Vol. 116, (1994), p. 3801

[2] T. Ishihara, H. Matsuda, and Y. Takita: Solid State Ionics Vol. 79, (1995), p. 147

[3] M. Feng, J.B. Goodenough, K. Huang and C. Milliken: J. Power Sources Vol. 63, (1996), p. 47

[4] T. Ishihara, H. Minami, H. Matsuda, H. Nishiguchi and Y. Takita: Chem. Commun. (1996), p. 929.

[5] S.L. Zhang, C.X. Li, C.J. Li, G.J. Yang and M.L. Liu: J. Power Sources Vol. 301 (2016), p. 62

[6] H.B. Sun, Y. Chen, F.L. Chen, Y.J. Zhang and M.L. Liu: J. Power Sources Vol. 301 (2016), p.199

[7] M. Feng and J.B. Goodenough: Eur J Solid State Inorg Chem Vol. 31 (1994), p. 663

[8] N. Trofimenko and H. Ullmann: Solid State Ionics Vol. 118 (1999), p. 215

[9] J. Drennan, V. Zelizko and D. Hay: J. Mater. Chem. Vol. 7 (1997), p. 79

[10] M. Lerch, H. Boysen and T. Hansen: J. Phys. Chem. Solids Vol. 62 (2001), p. 445.

[11] L. Vasylechko, V. Vashook, D. Savytskii, A. Senyshyn, R. Niewa and M. Knapp: J Solid State Chem Vol. (2003), p. 172

[12] P.R. Slater, J.T.S. Irvine, T. Ishihara and Y. Takita: J. Solid State Chem. Vol. 139 (1998), p. 135 